\title{
Expansion of European research capabilities in humidity measurement
}

\author{
Nedžadeta HODŽIĆ1,*, Semir ČOHODAREVIĆ ${ }^{1}$, Nebojša JANDRIĆ ${ }^{1}$, Radek STRNAD ${ }^{2}$, Danijel SESTAN ${ }^{3}$, \\ Davor ZVIZDIC ${ }^{3}$, Vito FERNICOLA ${ }^{4}$, Denis SMORGON $^{4}$, Luigi IACOMINI ${ }^{4}$, Slavica SIMIC $^{5}$, Dubaltach MAC \\ LOCHLAINN $^{6}$, Nuray KARABÖCE ${ }^{7}$, Seda OĞUZ AYTEKINN ${ }^{7}$,Jovan BOJKOVSKI ${ }^{8}$, Domen HUDOKLIN ${ }^{8}$, Olgica \\ PETRUŠOVA $^{9}$ and Tanja VUKICEVIC ${ }^{10}$
}

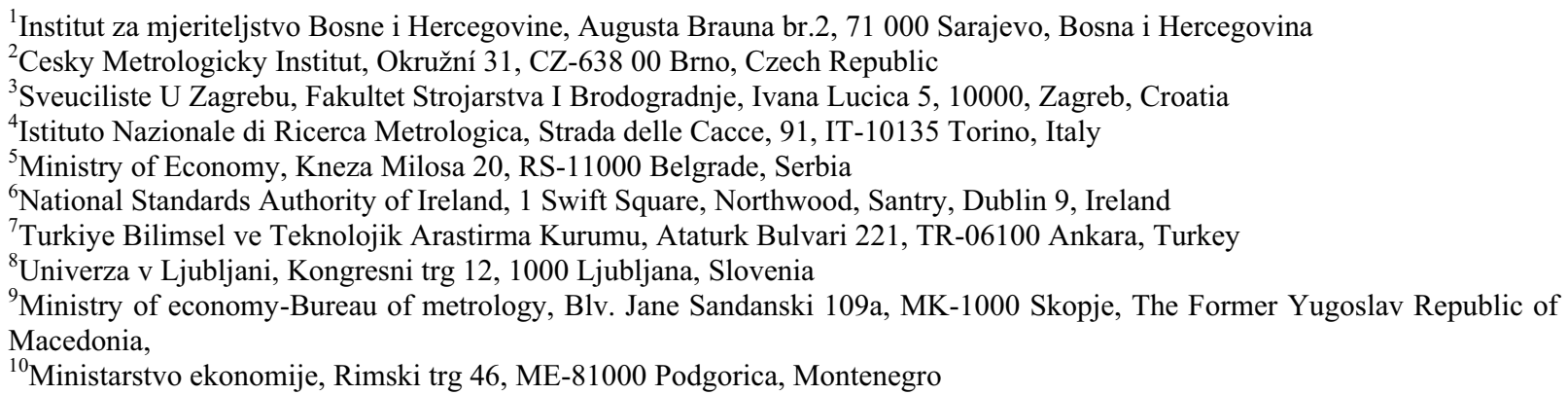

\begin{abstract}
Humidity is among the most important measured parameters related to HVAC applications, the storage of food products, industrial and medical gases, textile, paper and many other products requiring humidity measurement and control within certain limits. Humidity measurement techniques are diverse and each presents different challenges for use and calibration for a range of pressures and gases. Over the past few years, the development of humidity sensors and apparatus has matured to a level where traceable calibration is beneficial to all industries in which humidity and moisture measurement and control are important.
\end{abstract}

\section{Introduction}

Humidity measurement techniques are diverse and each presents different challenges for use and calibration for a range of pressures and gases. Over the past few years, the development of humidity sensors and apparatus has matured to a level where traceable calibration is beneficial to all industries in which humidity and moisture measurement and control are important.

This paper presents a new European project for Establishing the infrastructure for humidity measurements, assuring traceability and providing dissemination as important concepts in both developed and emerging NMI/DIs as well as a precondition to related research, industrial applications and quality standards as well as support for various services, including the grand challenges (health, environment and energy) and closely associated with quality of life measures and implementation of specific EU legislation. The overall objective of the project is to develop measurement and research capabilities in humidity measurements of participating emerging NMI countries, based on stakeholder's needs.

Specific objectives are: identifying existing and future needs, transfer of knowledge, developing measurement methods and sharing procedures as best practice, narrowing the gap of the offered calibration services, performing an inter-comparison, building research potential and strengthening the co-operation between the NMIs.

\section{Consortium overview}

The consortium consists of leading European NMI/DIs and emerging NMIs in the field of humidity in a

'Corresponding author: nedzadeta.hodzic@met.gov.ba

C) The Authors, published by EDP Sciences. This is an open access article distributed under the terms of the Creative Commons Attribution 
complementary metrology structure. The leading NMI/DIs of the consortium (INRIM-Italy, CMI-Czech Republic, TUBITAK-Turkey, FSB-Croatia and ULSlovenia) have significant experience and excellence in the area of humidity measurements and research. On the other side, the emerging NMIs have adequate equipment to carry out the project but limited experience and existing capabilities, particularly in humidity related research. Collaboration between those partners that are less experienced in research (IMBiH-Bosnia and Herzegovina, MoE-Serbia, NSAI-Ireland, ME-BoMThe Former Yugoslav Republic of Macedonia and MERMontenegro) and those that are more experienced and developed will develop the latter's metrology capabilities and infrastructure for traceable humidity measurements, which will support their participation in future research projects.

\section{Technical topics}

The project is performed within the framework of EURAMET/EMPIR (European Metrology Programme for Innovation and Research) and is divided into five work packages including, three technical and scientific work packages, and two work packages for the impact and management [1].

Table 1 summarizes the content of the different work packages.

Table 1: Work Packages Summary

\begin{tabular}{|l|l|}
\hline WPi & Work Package Title \\
\hline WP1 & $\begin{array}{l}\text { Improvements in the field of relative humidity } \\
\text { measurements }\end{array}$ \\
\hline WP2 & $\begin{array}{l}\text { Improvements in the field of dew point } \\
\text { measurements }\end{array}$ \\
\hline WP3 & Strategy development \\
\hline WP4 & Creating impact \\
\hline WP5 & Management and coordination \\
\hline
\end{tabular}

\section{Objectives overview}

The project addresses the following scientific and technical objectives:

\subsection{Relative humidity measurements}

The aim of this work package is to improve the measurement capabilities of participating NMI/DIs in the field of relative humidity and it addition to establish networking opportunities with industrial stakeholders within each country (related to knowledge exchange, traceability, skills and capacity building).

The aims of this work package are:
1. To perform a survey of the relative humidity related measurement needs of stakeholders in each country with an emerging NMI/DI. The results of the survey will be analysed and used as an input to the strategy for development in the field of humidity measurements in that country.

2. To develop an inner chamber for relative humidity calibrations, which will then be characterised by each of the partners.

3. To carry out an inter-comparison of the improved measurement capabilities developed by the partners in the field of relative humidity.

\subsection{Dew point temperature standards}

The aims of this work package are:

1. To obtain information about the dew point measurement related needs of stakeholders in each country with an emerging NMI/DI.

2. To obtain information about the existing level of knowledge and capabilities of partners and to identify gaps in the capabilities for dew point temperature measurement of the emerging NMI/DIs with regard to the stakeholder needs.

3. To improve the capabilities to enable emerging $\mathrm{NMI} / \mathrm{DIs}$ to perform dew point temperature measurements in the temperature range $-70{ }^{\circ} \mathrm{C}$ to $90{ }^{\circ} \mathrm{C}$.

\subsection{Strategy development}

The aims of this work package are:

1. To ensure that emerging countries engage in further development of humidity metrology infrastructure to support industrial needs, competitiveness and international trade and show commitment to sustainable growth in the partner's country after the lifetime of the project.

2. To ensure that emerging countries engage in future collaboration and co-operation, especially in future joint research and collaborative projects with European NMI/Dis.

3. To identify future trends toward smart specialisation in humidity metrology based on identified trends and needs for metrology research and services. 


\subsection{Impact}

Through the development of training courses in humidity measurement, the outcomes of the project, as well as general humidity measurement training will be delivered effectively to industrial stakeholders, thereby improving understanding and skills among industry within the European Union.

In the area of relative humidity and dew point measurement knowledge, transfer from experienced $\mathrm{NMI} / \mathrm{DIs}$ to those less experienced in how to use new types of humidity instruments and facilities will be very beneficial. It will help to raise the knowledge, measurement and research capabilities and will promote consistency within humidity metrology.

Through highlighting the importance of humidity to processes, and to human comfort levels, this project will lead to a better understanding of humidity among stakeholders and therefore to an improvement of environments with climate control, as well as humidity or moisture dependant industrial processes. A better understanding of humidity measurement and control will also allow the development of optimal storage conditions for produce, leading to a reduction in waste and spoilage throughout Europe.

\section{Research Highlights}

In recent years, the development of humidity sensors and equipment has matured to a level where traceable calibration is beneficial to all industries in which humidity, moisture measurement and control are important. Based on a significant experience in the area of humidity measurements the consortium is starting this cooperative scientific work according to a tight timeline. The following examples enable to highlight some research that will be done during the three year duration of the project.

\subsection{Relative humidity measurements}

Existing knowledge and expertise will be shared among the partners through their collaboration during the process of producing and characterising a small inner chamber, to be used within a larger temperature controlled enclosure, as well as through an intercomparison. The knowledge gathered in this work package will help the partners from emerging countries to further develop their capabilities by providing them with the skills and knowledge to build their own equipment for relative humidity measurements. By implementing the new chamber in their facilities, partners and other interested parties will have the opportunity to readily improve their capabilities in the field of relative humidity measurements by expanding the relative humidity and temperature ranges, achieving lower uncertainties and reducing calibration times.

\subsection{Dew point temperature standards}

In order to meet the objectives, two tasks are planned. In the first task a survey will be undertaken to identify the dew point related measurement needs of stakeholders in participating countries with an emerging NMI/DI (parameters to be investigated include temperature and pressure ranges and measurement media used). The second task builds upon the knowledge obtained about stakeholders' needs in order to improve the capacity of participating countries to perform high-accuracy dew/frost point measurements in the selected temperature range. Based on the stakeholders needs identified from the survey, gaps in the individual NMI/DIs' capabilities will be identified and areas targeted to achieve the improvement of the dew point measurement setups. The individual improvement will correspond to the industrial needs in the given country. The technical solution will be proposed by CMI in cooperation with INRIM and the participating NMI/DIs. The individual NMI/DIs will implement and test the designed solution with respect to the factors which could influence the measurement (flow rate, pressure, temperature, tubing, bath, media, etc.). A report detailing the influence of the different generator components on the uncertainty for dew point measurement using the improved setups will be prepared.

\subsection{Strategy development}

The key challenge in this work package is to prepare individual strategy documents for humidity research and development of the associated capabilities in Serbia, Bosnia and Herzegovina, Montenegro, Ireland, FYR Macedonia and Croatia (MoE, IMBiH, MER, NSAI, ME-BoM and FSB).

Each individual strategy document will be the long term strategy, over the next 15 years, taking into account future humidity measurement capability requirements and the need for developments linked with environmental, health and energy topics.

\section{Results}

Establishing traceable measurements in humidity at the level needed by each participating country will enable important inputs for areas of research, innovation and patenting in this field in future EMPIR projects. An important aspect of this project is the collaboration of less experienced NMI/DIs with experienced NMI/DIs. The latter will assist the emerging institutes in establishing their metrology capabilities in the field of humidity and will provide an appropriate internal knowledge transfer in humidity traceability at the primary and secondary level. An expansion of the capabilities in humidity measurements at the European level will be established through this project, meaning that more EURAMET member countries will be able to 
participate in inter-comparisons in the field of humidity and ensure smooth progression of approval of CMCs. It will widen the availability of traceability and services for humidity related measurements to more countries. All EURAMET members could be included in the roadmap for humidity and moisture measurement. At the same time, traceable calibration and measurement services will be provided to regional industry at a higher level than previously possible

\section{Acknowledgements}

The work presented here is funded through the European Metrology Programme for Innovation and Research (EMPIR). EMPIR is jointly funded by the EMPIR participating countries within EURAMET and the European Union.

\section{References}

[1] N. Hodzic \& al, JRP Protocol, 15RPT03 HUMEA, version date: 18 May 2016 